\title{
Operation analysis of microgrids using an orthogonal array- GA hybrid method
}

\author{
Seizi WATANABE* and Shin'ya OBARA** \\ * Kushiro College, National Institute of Technology \\ Otanozhike 2-32-1, Kushiro, Hokkaido 084-0916, Japan \\ E-mail: seiji@mech.kushiro-ct.ac.jp \\ ** Dep. of Electrical and Electronic Engineering, Kitami Institute of Technology \\ Koen-cho 165, Kitami, Hokkaido 090-8507, Japan
}

Received 23 February 2016

\begin{abstract}
The equipment and operation planning of a compound energy system (microgrid) with renewable energy sources is a dynamic, multivariate, nonlinear problem. Genetic algorithms (GA) provide a facile method for solving such problems and can be easily adapted to complicated energy systems; however, conventional GAs require a long runtime when the microgrid contains numerous energy sources and the solution must be highly accurate. This work introduces a preliminary step in which experimental design techniques, namely, an orthogonal array experiment and a factorial-effect chart are used to find an operation method that is close to the optimal solution for the energy system. The optimal operation solution is determined by using the operation method obtained from the orthogonal array experiment as the initial generation of chromosomes for the conventional GA. This proposed method does not find a strictly mathematical optimal solution, but the quasi-optimum solution is far more accurate than that from convention GAs and can be used industrially. The characteristics of the output power sources are found to strongly affect the analytic accuracy for the example of a microgrid.
\end{abstract}

Key words : Energy system, Microgrid, Orthogonal array, Genetic algorithm, Experimental design

\section{Introduction}

Decentralizing a vehicular energy system can decrease power transmission losses, effectively use the heat from exhaust, and promote the use of renewable energy. However, renewable energy systems must be stabilized by combining two or more power sources. Distributed energy microgrids have been studied widely: energy management strategies have been reported for a renewable energy-based residential microgrid (Pascual et. Al., 2015); an actual microgrid has been optimized in Iceland (Sachs and Sawodny, 2016); and a smartgrid has been reported, which was accompanied by various value-added features (Nair and Zhang, 2009, Anastasopoulos, Voulkidis, Vasilakos and Cottis, 1951, Hledik, 2009). The optimal operation of a compound energy system must integrate different energy networks and various power sources. In general, dynamic operation optimization is required because renewable energy systems must be able to store electricity and heat. In addition, the input-output characteristics of energy devices are often nonlinear, so the operation planning of a compound energy system is a dynamic, nonlinear, multivariate problem. Analysis methods have recently been developed to improve the operation optimization of energy systems; such methods include the conjugate gradient method, integer programming, and genetic algorithms (GA). Nazar and Haghifam (2009) has reported a multi-objective electric distribution system using a hybrid energy hub, GA has been used to optimize the control of hydrogen-fueled engines (Yang, Wang and $\mathrm{Li}, 2008$ ), and nonlinear programming theory was used to optimize the calibration of a hydrogen-fueled engine (Wang, He and Yang, 2010). Even though mixed-integer programming is a powerful analysis method, its application to the dynamic planning of energy storage requires complicated modifications.

In contrast, GA analysis is a facile method for solving dynamic, nonlinear, multivariate problems and can be easily adapted to a complex energy system (Obara, Watanabe and Rengaraja, 2011). When an analysis must incorporate a large number of energy sources and a high level of analytical accuracy, very long runtimes are required; this results from an 
increase in the number of chromosome models and the length of the genes contained therein. The objective of this paper is to develop a computer algorithm with industrially relevant accuracy that can control the operation of compound energy systems with many design parameters. That is, quasi-optimum solutions are obtained with a sufficient degree of analytical accuracy that can be used for short times. First, the proposed algorithm introduces an orthogonal array and factorialeffect chart (Taguchi, 2010), which are experimental design techniques, and determines an operation method that is close to the optimal solution of the compound energy system. The design of an energy system using experimental design techniques has only been reported previously (Lin and Lay, 2004, Yu, Wu and Shiah, 2008, Dante et. A., 1951). The nearoptimum operation method is entered into the chromosome models of the GA as initial values, and the conventional GA searches for the optimal operation parameters for the microgrid. The conventional GA searches the operation area near the optimal solution; when the initial value is chosen well, the optimal operation solution is obtained more efficiently than if the GA analysis method were used alone (Obara and Watanabe, 2011). This study also examines the effects of using various kinds of power sources, which exhibit different output characteristics, like the ratio of electric power to heat. The operation planning of the microgrid is solved for these different scenarios. The aim is to determine how differing power output characteristics affect the operation method and its analytical accuracy.

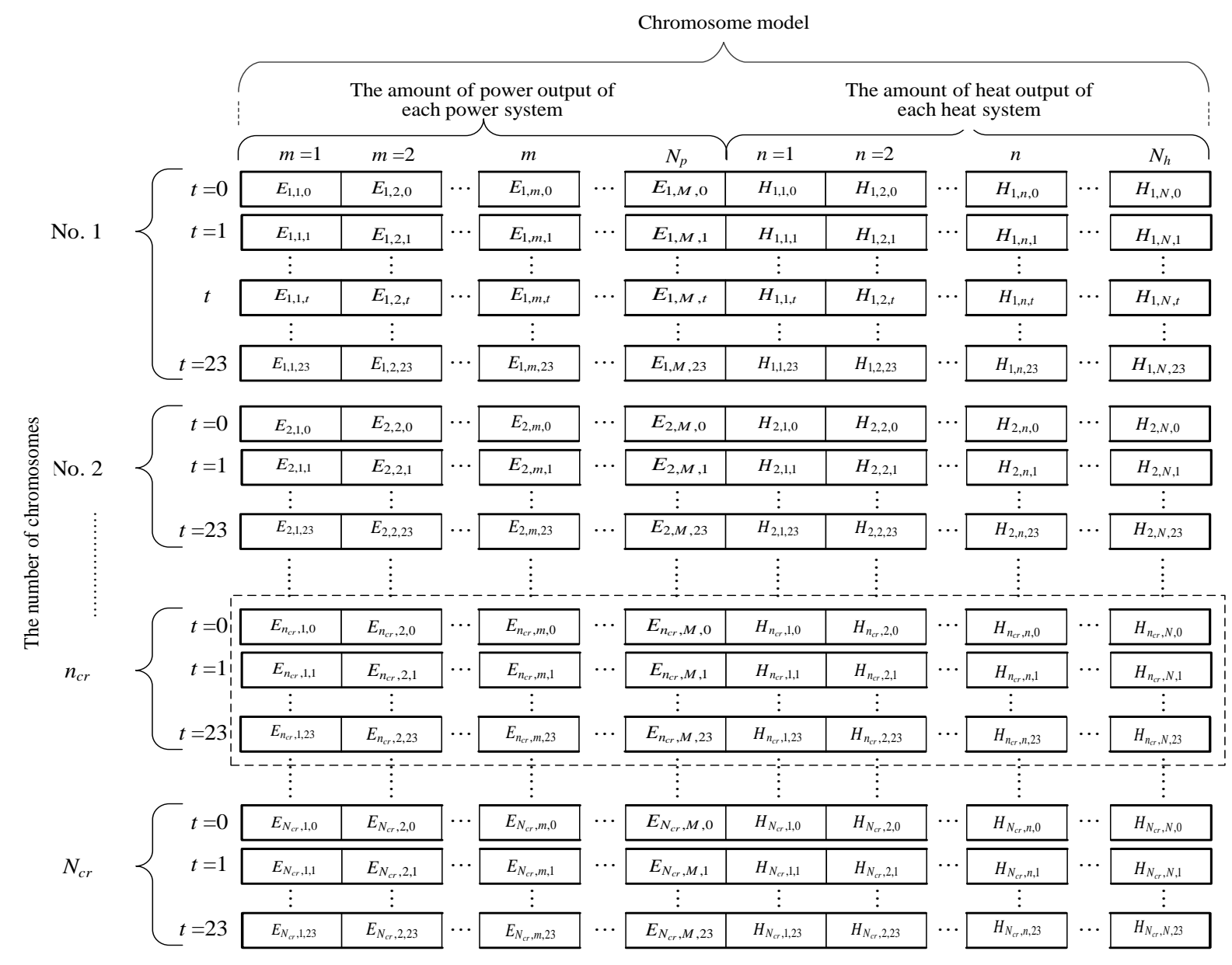

Fig. 1 Chromosome model using GA

\section{Analysis Methods}

The basic principle of the conventional GA and the orthogonal array-GA hybrid methods described below is the analysis method developed in the past by Obara and Watanabe (Obara and Watanabe, 2011, 2012).

\subsection{GA}

\subsubsection{Chromosome model}

The relationship between the input and output values of electric power and heat is shown in Eqs. (1) and (2) for the 
microgrid. The left-hand side of both equations gives the supply terms (for electric power or heat) at sampling time $t$, and the right-hand side comprises the consumption terms. The left-hand side of Eq. (1) accounts for electric power output via generators, such as an engine generator, a fuel cell, or a solar cell; the total number of electric generators is given by $M$. The left-hand side of Eq. (2) accounts for heat outputs, such as boilers, heat pumps, engine generators, and fuel cells, as well as the thermal power of heating equipment, such as solar heat. The number of heat outputs is given by $N_{h}$. The first term on the right-hand side of both Eqs. (1) and (2) is the demand; the second term is the total consumption of electric power and heat by the sum of all pieces of equipment $I$ and $J$, respectively.

The energy storage terms, such as accumulation of electricity and heat storage, are included in the second term on the right-hand side of each equation and the energy supply terms, such as the electric discharge of a battery and the heat output from a heat storage tank, are included in the left-hand side.

$$
\begin{aligned}
& \sum_{m=1}^{N_{p}} E_{m, t}+E_{b t, b t d, t}=E_{n e e d s, t}+E_{b t, b t c, t}+\sum_{i=1}^{I} \Delta p_{i, t} \\
& \sum_{n=1}^{N_{h}} H_{n, t}+H_{s t, o u t, t}=H_{n e e d s, t}+H_{s t, i n, t}+\sum_{j=1}^{J} \Delta h_{j, t}
\end{aligned}
$$

The power demand $E_{n e e d s, t}$ and heat demand $H_{\text {needs, } t}$ are fixed for a representative day, and $E_{m, t}$ and $H_{n, t}$ in Eqs. (1) and (2) are determined by the chromosome model of the GA, as shown in Fig. 1 . The chromosome model $n_{c r}$ of Fig. 1 consists of the outputs $E_{n_{c r}, m, t}$ and $H_{n_{c r}, n, t}$ from the generator $m$ and the heat source $n$, respectively, at sampling time $t$. Here $n_{c r}$ is the number of chromosomes, and $m$ and $n$ are the numbers of generators and heat sources, respectively. The region enclosed by a broken line in Fig. 1 is the genetic information included in one chromosome. The gene is written for the data $E_{n_{c r}, m, t}$ or $H_{n_{c r}, n, t}$, and the information on one chromosome represents the operation method for a single sampling time during a representative day of the target energy system.

The operation method of the battery and the heat storage tank at sampling time $t$ is influenced by the past $(t-1, t-$ $2, \ldots .$.$) operation methods. When the past operation methods of the system influence the future operation method, it is$ defined as the dynamic operation planning. The analysis example of this paper is a dynamic operation plan, because the operation period is shifted using a battery and a heat storage tank. As for the operation optimization by the GA of this paper, equipment operations at each sampling time are determined using the chromosome model of the GA. As for the proposal analysis method, the operation method of each equipment is decided using the predicted values of the load and renewable energy outputs.

\subsubsection{Objective function (adaptive value)}

A standard objective function for an energy system is given in Eq. (3). The cost of equipment, fuel expenses, environmental impact, and maintenance costs are all taken into consideration by the terms in Eq. (3). $\alpha_{1}, \alpha_{2}, \alpha_{3}$, and $\alpha_{4}$ are weighting factors; $\lambda$ is an operating period (year); and $C T_{m}, C T_{n}$, and $C T_{k}$ are the costs of generators, heat sources, and maintenance of the system for one year, respectively. $\theta_{p}$ and $\theta_{h}$ are the unit fuel prices of generators and heat equipment, respectively; $f_{m}$ and $f_{n}$ are the fuel consumptions of generators and heat equipment, respectively. On the right-hand side of Eq. (3), the second set of brackets in the second term denotes the environmental impact cost of the system. $\phi_{p}$ and $\phi_{h}$ are the costs accompanying the discharge of greenhouse gases by generators and heat equipment.

$$
\begin{aligned}
& F O B=\alpha_{1} \cdot\left(\sum_{m=1}^{N_{p}} C T_{m}+\sum_{n=1}^{N_{h}} C T_{n}\right)+\sum_{m h=1}^{12}\left\{\alpha_{2} \cdot \lambda \cdot \sum_{t=1}^{24}\left(\theta_{p} \cdot \sum_{m=1}^{N_{p}} f_{m, m h, t}+\theta_{h} \cdot \sum_{n=1}^{N_{h}} f_{n, m h, t}\right)\right. \\
& \left.+\alpha_{3} \cdot \lambda \cdot \sum_{t=1}^{24}\left(\phi_{p} \cdot \sum_{m=1}^{N_{p}} f_{m, m h, t}+\phi_{h} \cdot \sum_{n=1}^{N_{h}} f_{n, m h, t}\right)\right\}+\alpha_{4} \cdot \lambda \cdot C T_{k}
\end{aligned}
$$


Calculation of the payback period $\lambda_{p b}$, as shown in Eq. (4), is generally used to evaluate an energy system. $\theta_{\text {conv }}$ and $f_{\text {conv }}$ are the unit price and quantity of fuel consumption for the system. Eq. (3) was integrated into the objective function to retain flexibility in setting the values of $\theta_{\text {conv }}$ and $f_{\text {conv }}$.

$$
\lambda_{p b}=\left(\sum_{m=1}^{N_{p}} C T_{m}+\sum_{n=1}^{N_{h}} C T_{n}\right) / \sum_{m h=1}^{12}\left[\sum_{t=1}^{24}\left\{\theta_{c o n v} \cdot f_{c o n v, m h, t}-\left(\theta_{p} \cdot \sum_{m=1}^{N_{p}} f_{m, m h, t}+\theta_{h} \cdot \sum_{n=1}^{N_{h}} f_{n, m h, t}\right)\right\}\right]
$$

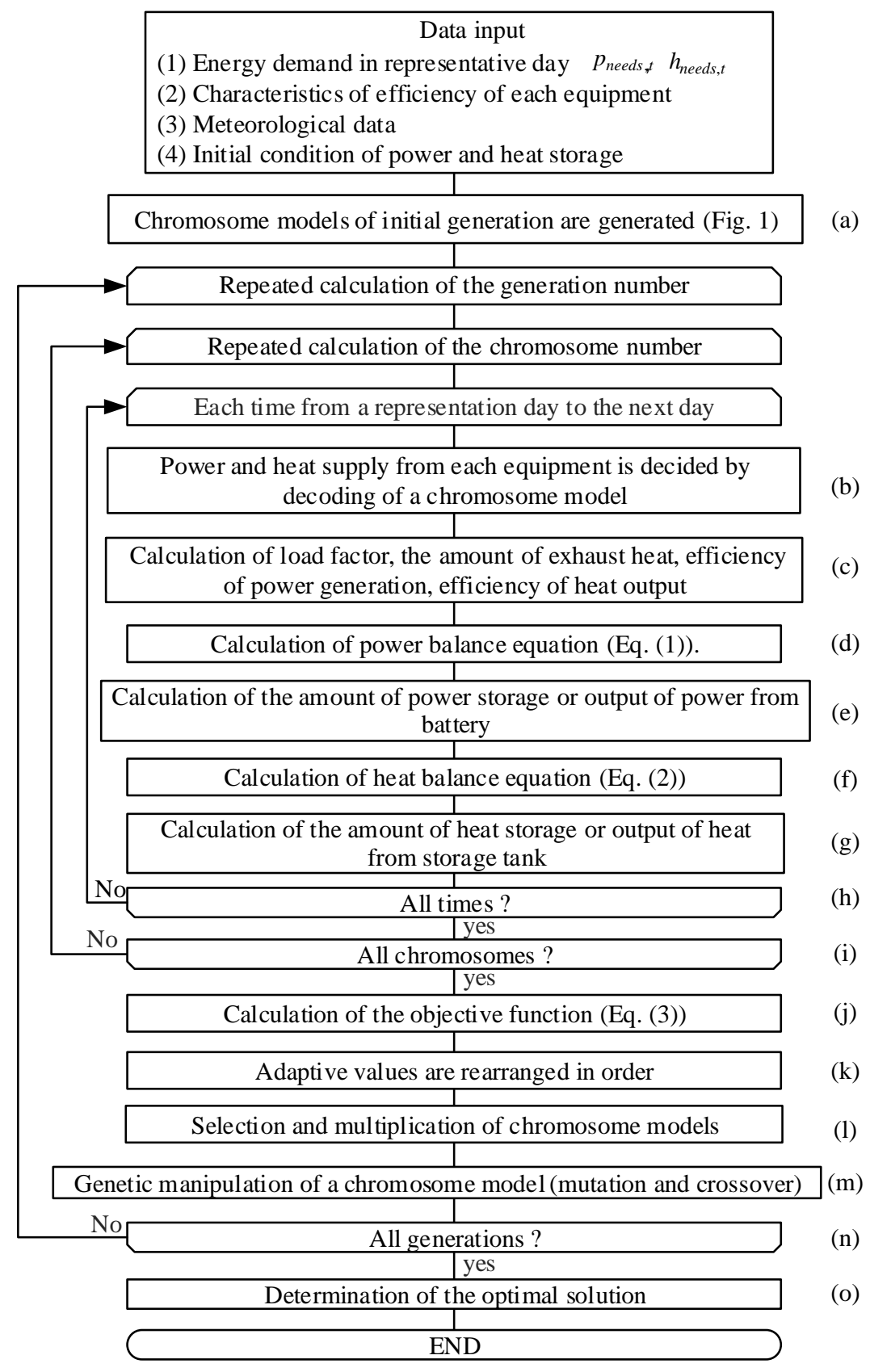

Fig. 2 Analysis flow using GA for a representative day

\subsubsection{Analysis flow}

The flow of the analysis that optimizes the operation of the energy system via GA is shown in Figure 2. First, many chromosome models of $N_{c r}$, described in Section 2.1.1, are randomly generated by a computer [Fig. 2(a)]. The electric power and heat outputs for each sampling time are determined by decoding these chromosome models [(Fig. 2(b)]. 
Quantifying the output characteristics of each piece of equipment enables the analysis to account for the load factor, the amount of exhaust heat, the power-generation efficiency, and the efficiency of thermal power [Fig. 2(c)]. The amount of electric-power storage or output to a battery is calculated by introducing these values into the power balance of Eq. (1) [Figs. 2(d) and (e)].

The heat energy describes the total amount of thermal power for each piece of heat equipment and is determined by decoding the chromosome model of the GA. The amount of exhaust heat from the generators is added to the heat balance in Eq. (2) [see Fig 2(f)] to calculate the total amount of heat that must be stored and the thermal capacity of the heat storage tank [Fig. 2(g)]. The operation method is determined by repeating the calculations from Fig. 2(b) - (g) for every sampling time during a representative day [Fig. 2(h)]. Moreover, the calculations from Fig. 2(b)-(h) are repeated for all of the chromosome models [Fig. 2(i)], and the adaptive value of Eq. (3) is calculated for each [Fig. 2(j)]. The chromosome models are then ordered based on their adaptive values [Fig. 2(k)]; chromosome models with low adaptive values are screened, and chromosome models with high adaptive values are increased [Fig 2(1)].

Chromosome models are randomly selected based on the prior probabilities of parent genes, which are manipulated by cross-over and mutation operations [Fig 2(m)] to diversify the $N_{c r}$ chromosome models. The calculations shown in Figs. 2(b)-(n) repeat for each generation, and an individual with the highest adaptive value among the final generation's chromosome models is chosen as the optimal solution [Fig. 2(o)].

\begin{tabular}{|c|c|c|c|c|c|c|c|c|c|c|c|c|c|}
\hline & \multicolumn{8}{|c|}{ Row number (Design parameter) } & \multicolumn{4}{|c|}{$\begin{array}{c}\text { Calculation results of } \\
\text { system fuel consumption }\end{array}$} \\
\hline & & (A) & (B) & (C) & (D) & (E) & (F) & (G) & (H) & $t 1$ & $t 2$ & $\cdots \cdots$ & $t 24$ \\
\hline \multirow{18}{*}{ 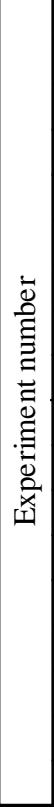 } & $e 1$ & 1 & 1 & 1 & 1 & 1 & 1 & 1 & 1 & $f_{e 1, t 1}$ & $f_{e 1, t 2}$ & $\ldots \ldots$ & $f_{e 1, t 24}$ \\
\hline & $e 2$ & 1 & 1 & 2 & 2 & 2 & 2 & 2 & 2 & $f_{e 2, t 1}$ & $f_{e 2, t 2}$ & $\cdots \cdots$ & $f_{e 2, t 24}$ \\
\hline & $e 3$ & 1 & 1 & 3 & 3 & 3 & 3 & 3 & 3 & $f_{e 3, t 1}$ & $f_{e 3, t 2}$ & $\cdots \cdots$ & $f_{e 3, t 24}$ \\
\hline & $e 4$ & 1 & 2 & 1 & 1 & 2 & 2 & 3 & 3 & $f_{e 4, t 1}$ & $f_{e 4, t 2}$ & $\cdots \cdots$ & $f_{e 4, t 24}$ \\
\hline & $e 5$ & 1 & 2 & 2 & 2 & 3 & 3 & 1 & 1 & $f_{e 5, t 1}$ & $f_{e 5, t 2}$ & …'. & $f_{e 5, t 24}$ \\
\hline & $e 6$ & 1 & 2 & 3 & 3 & 1 & 1 & 2 & 2 & $f_{e 6, t 1}$ & $f_{e 6, t 2}$ & …' & $f_{e 6, t 24}$ \\
\hline & $e 7$ & 1 & 3 & 1 & 2 & 1 & 3 & 2 & 3 & $f_{e 7, t 1}$ & $f_{e 7, t 2}$ & $\cdots \cdots$ & $f_{e 7, t 24}$ \\
\hline & $e 8$ & 1 & 3 & 2 & 3 & 2 & 1 & 3 & 1 & $f_{e 8, t 1}$ & $f_{e 8, t 2}$ & $\cdots \cdots$ & $f_{e 8, t 24}$ \\
\hline & $e 9$ & 1 & 3 & 3 & 1 & 3 & 2 & 1 & 2 & {$\left[f_{e 9, t 1}\right.$} & $f_{e 9, t 2}$ & …'. & $f_{e 9, t 24}$ \\
\hline & $e 10$ & 2 & 1 & 1 & 3 & 3 & 2 & 2 & 1 & $f_{e 10, t 1}$ & $f_{e 10, t 2}$ & …' & $f_{e 10, t 24}$ \\
\hline & $e 11$ & 2 & 1 & 2 & 1 & 1 & 3 & 3 & 2 & $f_{e 11, t 1}$ & $f_{e 11, t 2}$ & $\cdots \cdots$ & $f_{e 11, t 24}$ \\
\hline & $e 12$ & 2 & 1 & 3 & 2 & 2 & 1 & 1 & 3 & $f_{e 12, t 1}$ & $f_{e 12, t 2}$ & $\cdots \cdots$ & $f_{e 12, t 24}$ \\
\hline & $e 13$ & 2 & 2 & 1 & 2 & 3 & 1 & 3 & 2 & $f_{e 13, t 1}$ & $f_{e 13, t 2}$ & $\cdots \cdots$ & $f_{e 13, t 24}$ \\
\hline & $e 14$ & 2 & 2 & 2 & 3 & 1 & 2 & 1 & 3 & $f_{e 14, t 1}$ & $f_{e 14, t 2}$ & $\cdots \cdots$ & $f_{e 14, t 24}$ \\
\hline & $e 15$ & 2 & 2 & 3 & 1 & 2 & 3 & 2 & 1 & $f_{e 15, t 1}$ & $f_{e 15, t 2}$ & ..... & $f_{e 15, t 24}$ \\
\hline & $e 16$ & 2 & 3 & 1 & 3 & 2 & 3 & 1 & 2 & $f_{e 16, t 1}$ & $f_{e 16, t 2}$ & ...... & $f_{e 16, t 24}$ \\
\hline & $e 17$ & 2 & 3 & 2 & 1 & 3 & 1 & 2 & 3 & $f_{e 17, t 1}$ & $f_{e 17, t 2}$ & …' & $f_{e 17, t 24}$ \\
\hline & $e 18$ & 2 & 3 & 3 & 2 & 1 & 2 & 3 & 1 & $f_{e 18, t 1}$ & $f_{e 18, t 2}$ & $\cdots \cdots$ & $f_{e 18, t 24}$ \\
\hline
\end{tabular}

Fig. 3 Orthogonal L18 array

\subsubsection{GA analysis method}

Although GAs can solve nonlinear, multivariate problems, the analysis time becomes very long when the number of genes is increased. The increased runtime is necessary to accommodate an increase in the number of design parameters or to improve the analytical accuracy of the solution. Therefore, an orthogonal array and factorial-effect chart are used to select values of each design parameter that produce an operation scenario that is close to the optimum for the system. Then, the values of these design parameters are entered into a conventional GA, which searches for the optimal operation parameters. 
Experimental design aims to increase the efficiency of an experiment; the effect of each design parameter can be examined using an orthogonal array, without testing each combination of the design parameters. An example of the $\mathrm{L}_{18}$ orthogonal array is shown in Figure 3; design parameters in the same line of the orthogonal array are independent of each other. The orthogonal array is arranged specifically to ensure this independence so that the effect of each design parameter can be evaluated independently when each line of the orthogonal array is totaled. Orthogonal arrays greatly reduce the number of design-parameter combinations. In the $\mathrm{L}_{18}$ array, one design parameter can take either of two values (the level value) and seven design parameters can take any of three values. The total number of round-robin trials would be $2^{1} \times 3^{7}=4374$, but an $\mathrm{L}_{18}$ orthogonal array requires only 18 ( $e 1$ to $\left.e 18\right)$ trials of a design parameter [Fig. 3 (A)$(\mathrm{H})]$.

Table 1 Level of each design parameter

\begin{tabular}{cccc}
\hline Design parameters & First level & Second level & Third level \\
\hline (A) Parameter 1 & $x_{p 1,1}$ & $x_{p 1,2}$ & \\
(B) Parameter 2 & $x_{p 2,1}$ & $x_{p 2,2}$ & $x_{p 2,3}$ \\
(C) Parameter 3 & $x_{p 3,1}$ & $x_{p 3,2}$ & $x_{p 3,3}$ \\
(D) Parameter 4 & $x_{p 4,1}$ & $x_{p 4,2}$ & $x_{p 4,3}$ \\
(E) Parameter 5 & $x_{p 5,1}$ & $x_{p 5,2}$ & $x_{p 5,3}$ \\
(F) Parameter 6 & $x_{p 6,1}$ & $x_{p 6,2}$ & $x_{p 6,3}$ \\
(G) Parameter 7 & $x_{p 7,1}$ & $x_{p 7,2}$ & $x_{p 7,3}$ \\
(H) Parameter 8 & $x_{p 8,1}$ & $x_{p 8,2}$ & $x_{p 8,3}$ \\
\hline
\end{tabular}

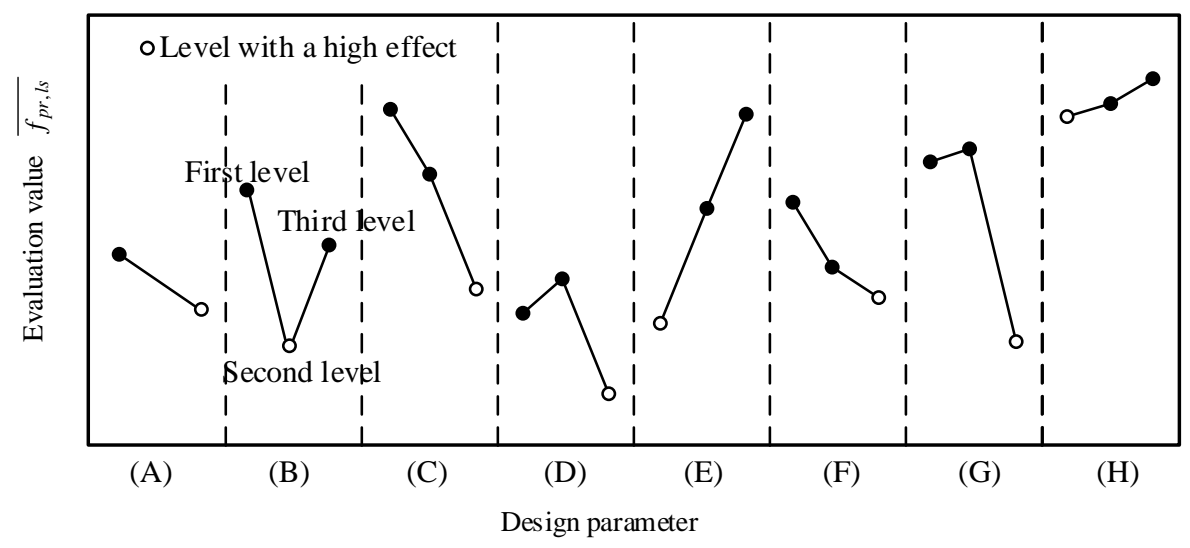

Fig. 4 Factorial effect chart

\subsubsection{Level values in the orthogonal array-GA hybrid analysis}

Level values of 1-3 for each design parameter are shown in the orthogonal array in Fig. 3 . The level values $x$ for each of the three levels of Parameters 1-8 are listed in Table 1. The level value table must be defined before the analysis is performed. For example, the level values of Parameter 2 are $x_{p 2,1}, x_{p 2,2}$, and $x_{p 2,3}$. The mean value of Parameter 2 is chosen to be $x_{p 2,2}$, and the minimum and maximum values are $x_{p 2,1}$ and $x_{p 2,3}$, respectively. Next, the evaluation value $f_{e k}(k=1,2, \ldots 18)$ is calculated from Eq. (5) for experiments $e 1$ to $e 18$ using the level values of Table 1 for each design parameter in the orthogonal array [Fig. $3(\mathrm{~A})-(\mathrm{H})$ ].

$$
f_{e k}=\sum_{t=1}^{24} f_{e k, t}=\sum_{t=1}^{24}\left(\sum_{m=1}^{N_{p}} f_{m, t}+\sum_{n=1}^{N_{h}} f_{n, t}\right)
$$

\subsubsection{Determination of the initial values of the GA using a factorial-effect chart}


The average evaluation value for the given level value $l s$ of a design-parameter $p l$ is $\overline{f_{p r} l s}$. For example, the average evaluation value $\overline{f_{(B), 2}}$ of the second level of design parameter $(\mathrm{B})$ is the average of the evaluation values from $e 4, e 5, e 6, e 13, e 14$, and $e 15$ for the experiment numbers $f_{e 4}, f_{e 5}, f_{e 6}, f_{e 13}, f_{e 14}$, and $f_{e 15}$ in Fig. 3. The factorial-effect chart shown in Fig. 4 is an example taken from this result. Suppose $\overline{f_{p r}, l s}$ yields a small value for an objective function, the level that is closest to an optimal solution [for design parameters $(\mathrm{A})-(\mathrm{H})$ ] is set to the level values of the white round head in Fig. 4. Level values that are close to the optimal solution are described as high level values.

The design parameter (B) in Fig. 4 appears to have an optimal solution in the second level (namely, near the average value) in Table 2. (A), (C), (D), (F), and (G) have optimal solutions in the third level (namely, near the maximum values). It appears that $(\mathrm{E})$ and $(\mathrm{H})$ have optimal solutions in the first level (namely, near the minimum values). In this study, the high level value of each high design parameter is used as the initial value in the chromosome models of the GA described in Section 2.1.1. The analysis efficiency is expected to increase significantly because the search range of the GA is concentrated near optimum values.

Table 2 Efficiency of each equipment

\begin{tabular}{ll}
\hline Solar cell (with power conditioner) $\varphi_{c d, t}$ & 0.15 \\
Heat storage tank $\varphi_{s t, i n, t}, \varphi_{s t, o u t, t}$ & 0.8 \\
Battery (efficiency of charge and discharge) $\quad \varphi_{b t c}, \varphi b t d$ & 0.9 \\
Power conditioner using Fuel cell (SOFC and PEFC) and & 0.9 \\
G/E generator (included to $\left.E_{f c, t}, E_{g e, t}\right)$ & \\
Power transmission of power grid & 1.0 \\
Heat supply to heat grid & 1.0 \\
\hline
\end{tabular}

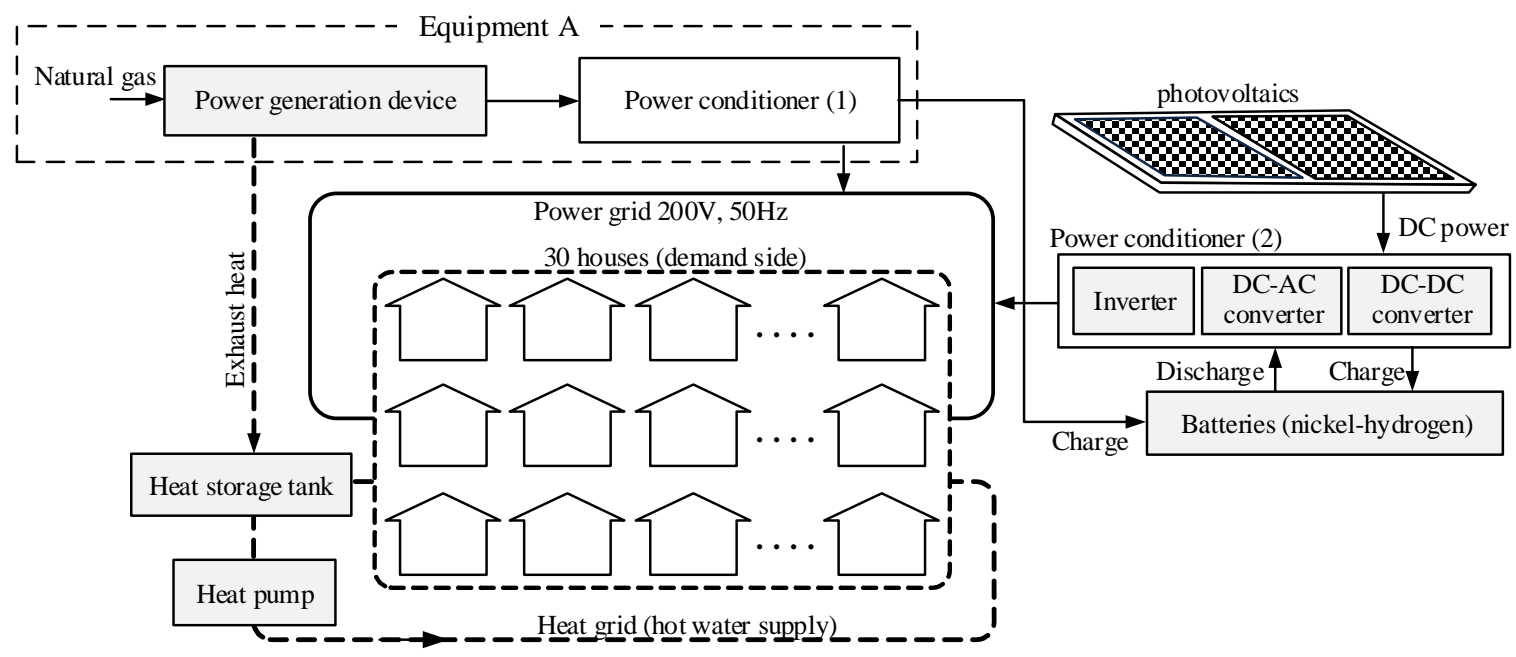

Fig. 5 Independent microgrid system scheme

\section{Case study \\ 3.1 System outline}

An interconnected microgrid with two or more energy sources is shown in Fig. 5. The power supply for the energy system exhibits nonlinear characteristics. The system in Fig. 5 supplies electric power and heat to 30 residences using various energy sources; the operation of the microgrid is optimized using both conventional GA and the proposed algorithm to draw a comparison. The microgrid in Fig. 5 consists of an electric-power grid and a heat grid (hot water). The system comprises a fuel cell [solid oxide fuel cell (SOFC) or a proton-exchange membrane fuel cell (PEFC)] or a gas-engine generator (G/E generator), photovoltaics, power conditioners (1) and (2), a heat pump, a battery, and a heat storage tank. The type of generator that is used as Equipment A in Fig. 5 depends on the power conditioner (1); the equipment related to each power supply is shown in Fig. 6. 


\subsection{Electric power supply system}

When natural gas is supplied to a fuel cell or a G/E generator, alternating-current electric power (at $200 \mathrm{~V}$ and $50 \mathrm{~Hz}$ ) will be input to the electric-power grid from power conditioner (1). Moreover, the output of the fuel cell or the G/E generator is controlled by adjusting the supply of natural gas. The power-generation efficiency of this equipment depends on the load factor; the relationship between the load factor and the efficiency of each generator (Fig. 7) is used to determine the output of electric power and heat (Maeda, Masumoto and Hayano, 2010, Wakui and Yokoyama, 2011, NEDO, 2009 NEDO, 2009). When the output characteristics shown in Fig. 7(a)-(c) are used, the output ratio of electric power and heat can be obtained from the load factor of each power source. Idling operation is assumed as correspondence of the rapid increase in load of a fuel cell. However, the fuel consumed by this operation mode is not taken into consideration. This analysis does not account for the effects of scaling each power supply. When photovoltaics are used to supply power to the grid via power conditioner (2) in Fig. 5, excess electric power can be stored in the battery.

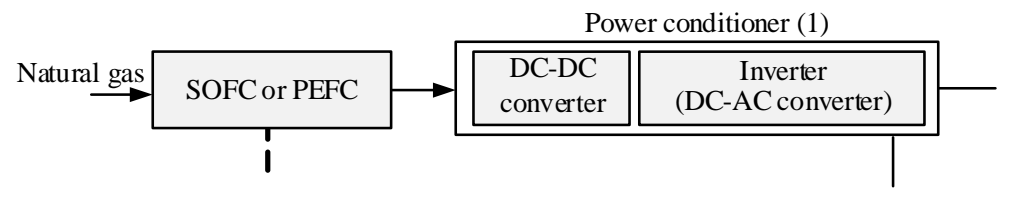

(a) Fuel cell

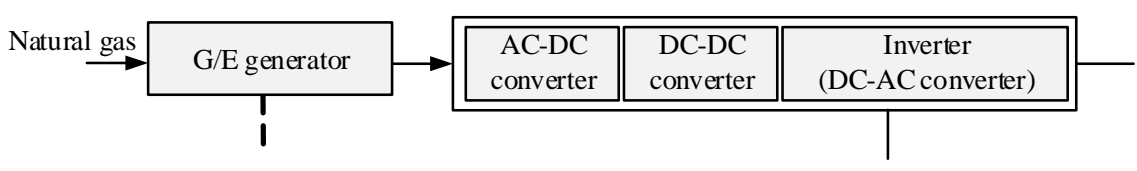

(b) G/E generator

Fig. 6 Equipment A

\subsection{Heat supply system}

The heat sources in the system are exhausted from the power sources, like the fuel cell, and an air-source heat pump. When exhaust heat is stored, it can be supplied to the demand side with a time-shift operation.

\subsection{Energy flow of the system}

\subsubsection{Energy balance equation}

Equations (6)-(11) are the balances for electric power and heat in the microgrid shown in Fig. 5. The left-hand sides and the right-hand sides of each equation are input and output terms, respectively. The right-hand sides $E_{n e e d, t}$ and $H_{\text {need }, t}$ of each equation are the demands of electric power and heat; the load pattern is used for the average residence in Sapporo, Japan during February (winter) (see Fig. 8) (Narita, 1996). The electric power and heat demands in February are much larger than during the summer season. Electric lamps and household appliances are encompassed by the power load; water heaters and space heaters are encompassed by the heating load. Losses from power conditioner (1) are included in the output of the power source $E_{f c, t}$ or $E_{g e, t}$ for sampling time $t . H_{\text {rad,t }}$ is the heat loss (heat radiation) from a heat storage tank. The heat storage loss set efficiency of thermal storage $95 \%$ (mixed tank type heat storage), and took $5 \%$ of loss into consideration.

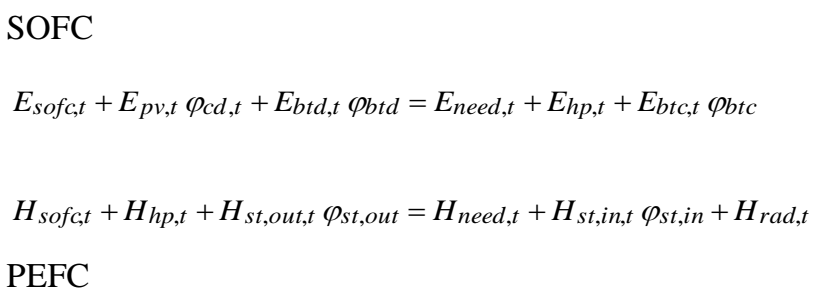




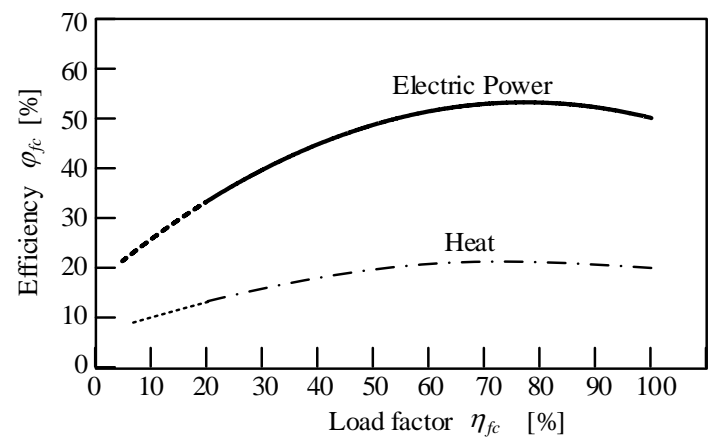

(a) SOFC (NEDO, 2009)

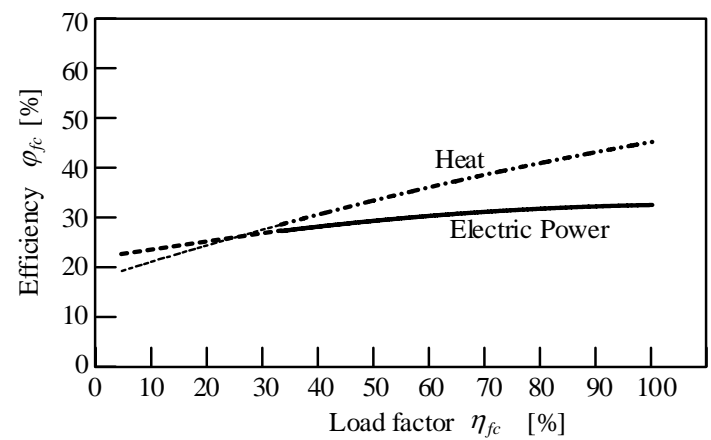

(b) PEFC (Maeda, et al., 2010)

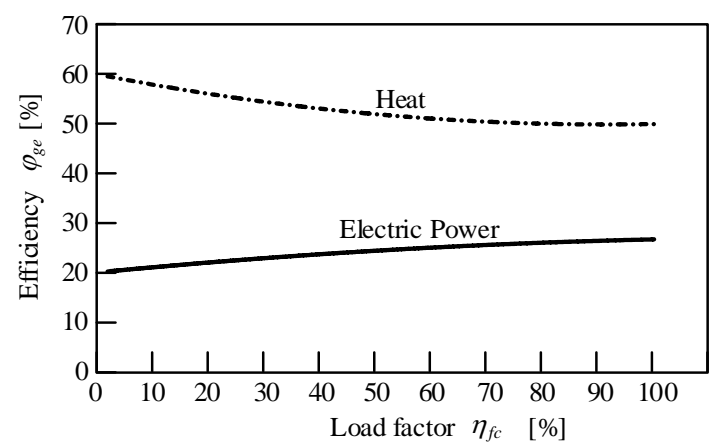

(c) G/E generator (Wakui and Yokovama, 2011)

Fig. 7 Performance of each generator

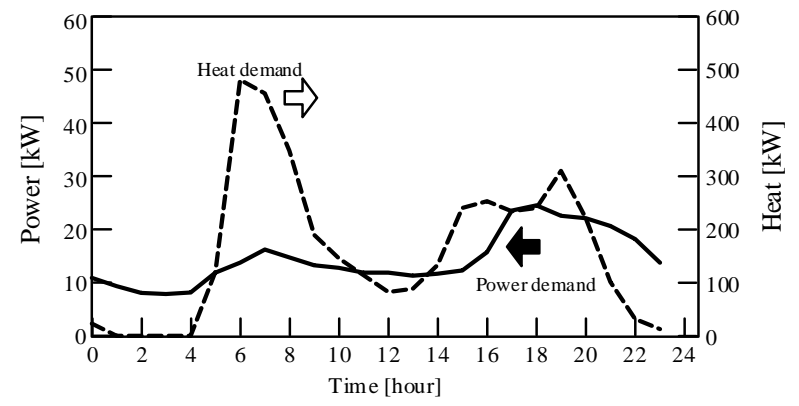

Fig. 8 Energy demand of a 30-house microgrid during February in Sapporo, Japan (Narita, 1996)

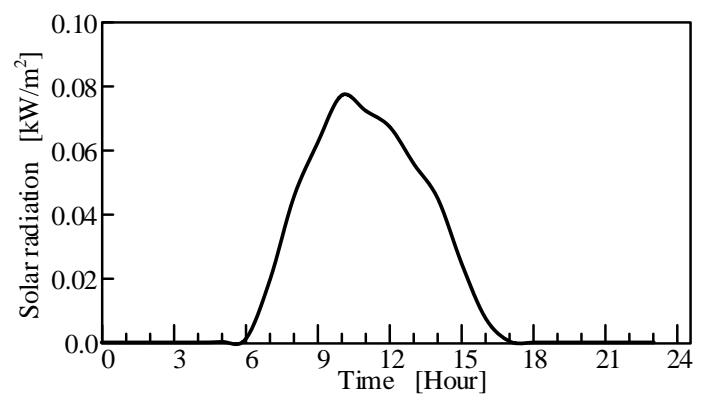

Fig. 9 Solar radiation during February in Sapporo (NEDO, 2016)

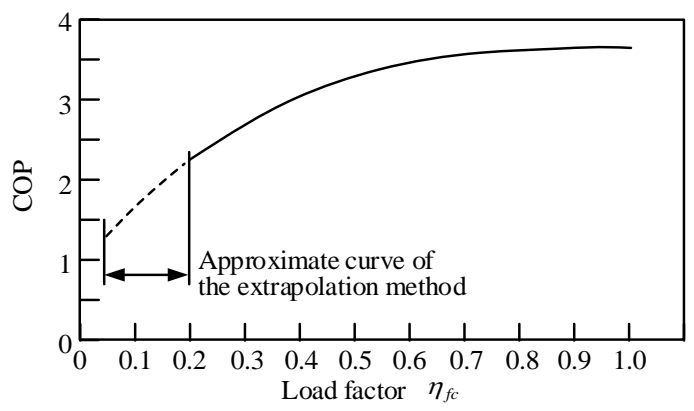

Fig. 10 Performance of a heat pump system (Mitsubishi Electric, 2016)

$$
\begin{aligned}
& E_{p e f c, t}+E_{p v, t} \varphi_{c d, t}+E_{b t d, t} \varphi_{b t d}=E_{n e e d, t}+E_{h p, t}+E_{b t c, t} \varphi_{b t c} \\
& H_{p e f c, t}+H_{h p, t}+H_{s t, o u t, t} \varphi_{s t, o u t}=H_{n e e d, t}+H_{s t, i n, t} \varphi_{s t, i n}+H_{r a d, t}
\end{aligned}
$$

Gas engine generator

$$
\begin{aligned}
& E_{g e, t}+E_{p v, t} \varphi_{c d, t}+E_{b t d, t} \varphi_{b t d}=E_{n e e d, t}+E_{h p, t}+E_{b t c, t} \varphi_{b t c} \\
& H_{g e, t}+H_{h p, t}+H_{s t, o u t, t} \varphi_{s t, o u t}=H_{\text {need }, t}+H_{s t, i n, t} \varphi_{s t, i n}+H_{\text {rad }, t}
\end{aligned}
$$

\subsubsection{Output characteristics of the generators}

The load factor for a power source is given by Equation (12); Eqs. (13)-(16) give the power-generation efficiency and fuel consumption of each power source. When the load factor $\eta_{f c, t}$ (or $\eta_{g e, t}$ ) obtained from Eq. (14) is substituted into Eqs. (13)-(15), the power-generation efficiency $\varphi_{f c, \eta_{f c, t}}$ or $\varphi_{g e, \eta_{g e, t}}$ is obtained. $C_{f c}$ (or $C_{g e}$ ) is the rated capacity of the power source. The value of each coefficient in Eq. (13)-(15) is obtained from an approximate expression of the output characteristics of each power source shown in Fig. 7. Approximated curves (broken lines) show the powergeneration efficiency $\varphi_{f c, \eta_{f, t,}}$ of load factors below the lower limit of the fuel cell shown in Figs. 7(a) and (b). The fuel consumption $F_{f c, t}$ (or $F_{g e, t}$ ) of each power source is obtained by substituting the power-generation efficiency $\varphi_{f c, \eta_{f c, t}}$ 
(or $\varphi_{g e, \eta_{g e, t}}$ ) calculated from Eqs. (13)-(15) into Eq. (16). $\dot{E}$ is the hourly electric power.

$$
\begin{aligned}
& \eta_{f c, t}=E_{f c, t} / C_{f c} \text { or } \eta_{g e, t}=E_{g e, t} / C_{g e} \\
& \text { SOFC: } \varphi_{f c, \eta_{f c, t}}=-6.11 \times 10^{-5} \eta_{f c, t}^{2}+9.46 \times 10^{-3} \eta_{f c, t}+0.167 \\
& \text { PEFC: } \varphi_{f c, \eta_{f c, t}}=-8.90 \times 10^{-6} \eta_{f c, t}^{2}+1.97 \times 10^{-4} \eta_{f c, t}+0.2171 \\
& \text { G/E generator: } \varphi_{g e, \eta_{g e, t}}=-4.20 \times 10^{-6} \eta_{g e, t}^{2}+1.09 \times 10^{-3} \eta_{g e, t}+0.20 \\
& F_{f c, t}=\dot{E}_{f c, t} / \varphi_{f c, \eta_{f c, t}} \text { or } F_{g e, t}=\dot{E}_{g e, t} / \varphi_{g e, \eta_{g e, t}}
\end{aligned}
$$

Equations (12)-(16) give the thermal power of each power source $H_{f c, t}$ (or $H_{g e, t}$ ), which is obtained from substitution of the value in Eqs. (10)-(14).

$$
\begin{aligned}
& \text { SOFC: } \quad H_{f c, t}=-2.45 \times 10^{-5} \eta_{f c, t}{ }^{2}+3.78 \times 10^{-3} \eta_{f c, t}+0.0667 \\
& \text { PEFC: } \quad H_{f c, t}=-7.99 \times 10^{-6} \eta_{f c, t}{ }^{2}+3.56 \times 10^{-3} \eta_{f c, t}+0.177
\end{aligned}
$$

G/E generator: $\quad H_{g e, t}=1.22 \times 10^{-5} \eta_{g e, t}{ }^{2}-2.23 \times 10^{-3} \eta_{g e, t}+0.6013$

Figure 9 shows the example of the amount of global solar radiation of Sapporo in February representation days. Because the maximum in Fig. 9 was $0.08 \mathrm{~kW} / \mathrm{m}^{2}$, the weather is a very bad example and the analysis example was investigated regarding the severest conditions of photovoltaics.

\subsubsection{Operation of the heating equipment}

The load factor of a heat pump is given by Eq. (20); Equations (21) and (22) give the coefficient of performance (COP) and power consumption, respectively, for the heat pump shown in Fig. 10. COPhp,t is obtained by substituting the load factor $\eta_{h p, t}$ from Eq. (20) into Eq. (21). The power consumption $E_{h p, t}$ is obtained by substituting $C O P_{h p, t}$ and $H_{h p, t}$ into Eq. (22).

$$
\begin{aligned}
& \eta_{h p, t}=H_{h p, t} / C_{h p} \\
& C O P_{h p, t}=2.70 \times 10^{-6} \eta_{h p, t}^{3}-8.11 \times 10^{-4} \eta_{h p, t}^{2}+0.0813 \eta_{h p, t}+0.879 \\
& E_{h p, t}=-H_{h p, t} / C O P_{h p, t}
\end{aligned}
$$

When the thermal power of the power source exceeds heat demand $\left(H_{f c, t}>H_{\text {need }, t}\right.$ or $\left.H_{g e, t}>H_{\text {need,t }}\right)$, the heat pump stops, and the excess heat ( $H_{s t, i n, t}=H_{f c, t}-H_{n e e d, t}$ or $\left.H_{s t, i n, t}=H_{g e, t}-H_{n e e d, t}\right)$ is stored in the heat storage tank. However, when the total amount of excess heat exceeds the storage capacity $C_{s t}$, it is transferred to the air from a radiator $\left(H_{\text {rad }, t}\right)$. On the other hand, when the thermal power of a power source is less than heat demand $\left(H_{f c, t}<H_{\text {need }, t}\right.$ or $\left.H_{\text {ge,t }}<H_{\text {need }, t}\right)$, the stored heat $H_{s t, \text { out }, t} \cdot \varphi_{s t, \text { out }}$ is supplied to the demand side. When the combined thermal output from the power source and the heat storage tank do not fulfill heat demands $\left(H_{f c, t}+H_{s t, \text { out }, t} \varphi_{s t, \text { out }}<H_{\text {need }, t}\right.$ or $\left.H_{g e, t}+H_{s t, \text { out }, t} \varphi_{s t, \text { out }}<H_{\text {need }, t}\right)$, the heat pump compensates by producing heat $H_{h p, t}$. When $H_{h p, t}$ is fixed, the power consumption $E_{h p, t}$ of the heat pump is determined by Eqs. (20)-(22).

\subsection{Analysis conditions}


The efficiency of each piece of equipment in the microgrid in Fig. 5 is listed in Table 2. The differences between operation methods based on the type of power source are computed by assuming that the electrical and heat losses are the same; they are not taken into consideration during the analysis. Nor does the analysis consider changes in the conversion efficiency of the solar cell depending on the surface temperature.

The battery can respond to a time shift of electric-power supply and demand, and control of a short time of fluctuations by photovoltaics. However, in the analysis of this paper, only the time shift of electric-power supply and demand is taken into consideration to evaluation of battery capacity. Because the electric-power quality (frequency, voltage, higher harmonic wave) of a microgrid is influenced by electric-power fluctuations, the evaluation of the battery capacity based on the stability of the electric power by several $10 \mathrm{~ms}$ sampling requires. In the analysis case of this paper, in order to investigate the operation plan of a microgrid, sampling time is set into every hour. To take into consideration control of the electric-power fluctuation by a battery, it is necessary to shorten the sampling period further.

\subsection{The level of the design parameters}

The $\mathrm{L}_{18}$ array can accommodate eight design parameters and is used for the orthogonal array-GA hybrid analysis method in this example. The design parameters are (A)-(G) in Table 3. The solar cell [design parameter (A)] has two levels, and other equipment [design parameters (B)-(G)] has three levels. The rated capacity of each piece of equipment, the amount of battery discharge $E_{b t d, t}$, and the amount of charge $E_{b t c, t}$ are all design parameters. The capacity $C_{p v}$ of the solar cell has a maximum (the second level) of $100 \mathrm{~kW}$ based on an average usage of $3.3 \mathrm{~kW}$ per residence. In the factorial-effect chart (Fig. 11), design parameters with only two levels cannot exhibit an inflection point but design parameters with three levels can; therefore, we only apply the two levels of the orthogonal array to the design parameter without an inflection point, photovoltaics.

Design parameters (B), (E), (F), and (G) are the capacity $C_{b t}$ of a battery, the capacity $C_{f_{c}}$ or $C_{g e}$ of a power source, the capacity $C_{s t}$ of a heat storage tank, and the capacity $C_{h p}$ of a heat pump, respectively. The minimum (first level) of the heat storage tank is 0 , indicating no heat storage. The first level of the amount of electric discharge of a battery $E_{b t d, t}$ and the amount of charge $E_{b t c, t}$ are also set to 0 . The maximum of each design parameter was decided based on the maximum load of electric power and heat. The capacity of the G/E generator was determined based on the difference in power-generation efficiency between the G/E generator and the fuel cell shown in Fig. 7.

Table 3 Parameters of design and level

\begin{tabular}{lccc}
\hline \multicolumn{1}{c}{ Parameters of design } & First level & Second level & Third level \\
\hline (A) Capacity of photovoltaic $C_{p v}[\mathrm{~kW}]$ & 0 & 100 & \\
(B) Capacity of battery $C_{b t}[\mathrm{kWh}]$ & 5 & 15 & 25 \\
(C) Amount of battery discharge $E_{b t d}[\mathrm{~kW}]$ & 0 & 4 & 8 \\
(D) Amount of battery charge $E_{b t c}[\mathrm{~kW}]$ & 0 & 4 & 8 \\
(E) Capacity of fuel cell $C_{f c}[\mathrm{~kW}]$ & 350 & 400 & 450 \\
Capacity of G/E generator $C_{g e}[\mathrm{~kW}]$ & 700 & 750 & 800 \\
(F) Capacity of heat storage tank $C_{s t}[\mathrm{kWh}]$ & 0 & 100 & 200 \\
(G) Capacity of heat pump $C_{h p}[\mathrm{~kW}]$ & 500 & 600 & 700 \\
\hline
\end{tabular}

Table 4 Analysis ranges of each design parameter

\begin{tabular}{lccc}
\hline \multicolumn{1}{c}{ Parameters of design } & SOFC & PEFC & G/E generator \\
\hline (A) Capacity of photovoltaic $C_{p v}[\mathrm{~kW}]$ & 0 & 0 & 0 \\
(B) Capacity of battery $C_{b t}[\mathrm{kWh}]$ & $7.5-17.5$ & $7.5-17.5$ & $7.5-17.5$ \\
(C) Amount of battery discharge $E_{b t d}[\mathrm{~kW}]$ & $2.0-6.0$ & less than 8 & less than 8 \\
(D) Amount of battery charge $E_{b t c}[\mathrm{~kW}]$ & 0 & 0 & 0 \\
(E) Capacity of fuel cell $C_{f c}[\mathrm{~kW}]$ & less than 350 & less than 450 & \\
$\quad$ Capacity of G/E generator $C_{g e}[\mathrm{~kW}]$ & & & less than 800 \\
(F) Capacity of heat storage tank $C_{s t}[\mathrm{kWh}]$ & less than 100 & less than 200 & less than 200 \\
(G) Capacity of heat pump $C_{h p}[\mathrm{~kW}]$ & less than 500 & less than 500 & $550-650$ \\
\hline
\end{tabular}




\subsection{Objective function (adaptive value)}

Equation (23) presents an objective function for the system; in this analysis, it is defined as the minimization of fuel consumption on a representative day. The fuel consumption of the system is due to the power supply in Fig. 5 .

$$
\sum_{t=0}^{24} f_{f c, t} \rightarrow \text { minimize or } \quad \sum_{t=0}^{24} f_{g e, t} \rightarrow \text { minimize }
$$

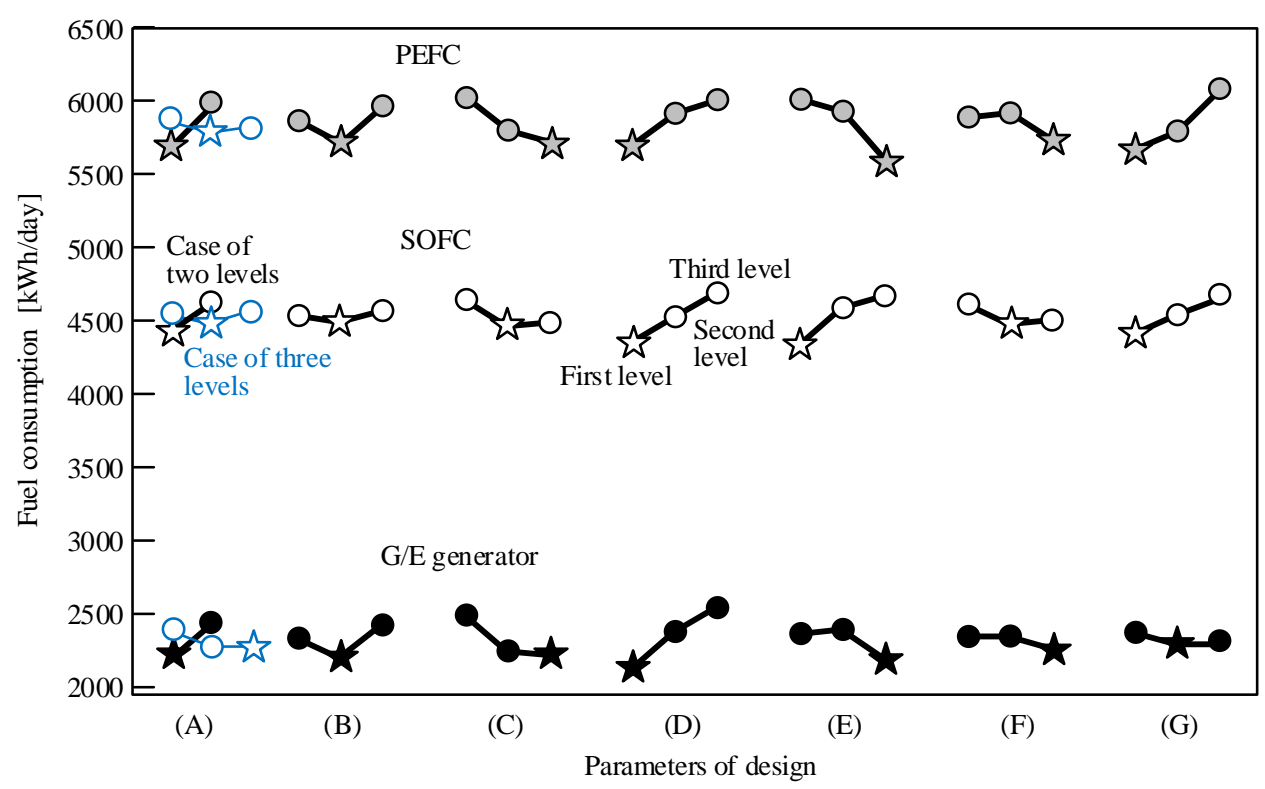

Fig. 11 Factor effect chart

\subsection{Initial values used for the orthogonal array-GA hybrid analysis}

Each level value of each design parameter in Table 3 is described by the $\mathrm{L}_{18}$ orthogonal array in Fig. 3. The factorialeffect chart for the design parameters (A)-(G) in an orthogonal array experiment is shown in Fig. 11. The symbol "色”, denotes a level that most strongly contributes to the reduction of system-wide fuel consumption. The optimal solution is obtained by searching the GA within the neighborhood of these level values. Based on the results of Fig. 11, the chromosome model group of the initial generation is set as the values or ranges in Table 4. For example, the fuel consumption is reduced most for any power supply when the second level of the battery capacity $C_{b t}$ is $15 \mathrm{~kW}$ [Fig. 11(B)]. Accordingly, the range of battery capacity of the initial chromosome model is set as 7.5 to $17.5 \mathrm{~kW}$.

\begin{tabular}{lccc}
\multicolumn{4}{c}{ Table 5 Optimum design parameters of proposal system } \\
\hline \multicolumn{1}{c}{ Parameters of design } & SOFC & PEFC & $\begin{array}{c}\text { G/E } \\
\text { generator }\end{array}$ \\
\hline (A) Capacity of photovoltaic $C_{p v}[\mathrm{~kW}]$ & 0 & 0 & 0 \\
(B) Capacity of battery $C_{b t}[\mathrm{kWh}]$ & 0 & 0 & 0 \\
(C) Amount of battery discharge $E_{b t d}[\mathrm{~kW}]$ & 0 & 0 & 0 \\
(D) Amount of battery charge $E_{b t c}[\mathrm{~kW}]$ & 0 & 0 & 0 \\
(E) Capacity of fuel cell $C_{f c}[\mathrm{~kW}]$ & 146 & 142 & 769 \\
Capacity of G/E generator $C_{g e}[\mathrm{~kW}]$ & & & 62 \\
(F) Capacity of heat storage tank $C_{s t}[\mathrm{kWh}]$ & 66 & 0 & 0 \\
(G) Capacity of heat pump $C_{h p}[\mathrm{~kW}]$ & 469 & 454 & 1910 \\
\hline Fuel consumption $f_{f c}, f_{g e}[\mathrm{kWh}]$ & 3210 & 4692 & \\
\hline
\end{tabular}

\subsection{Analysis parameters of the GA}


There are 40 generations and 300 chromosomes, and the probability of mutations and cross-overs is 0.3 . These solution parameters were decided by applying the trial-and-error method to the analysis.

\section{Analysis Results and Discussion 4.1 Planning the equipment capacity}

The analysis results are given in Table 5 when the analysis ranges in Table 4 are used as the initial values for the conventional GA. The capacity of the G/E generator is significantly larger than the SOFC and PEFC because operation of the G/E generator generates more heat. In contrast, fuel cells exhaust a small amount of heat, and the heat pump is required.

Table 6 Optimum design parameters of proposal system with photovoltaics

\begin{tabular}{lccc}
\hline \multicolumn{1}{c}{ Parameters of design } & SOFC & PEFC & G/E generator \\
\hline (A) Capacity of photovoltaic $\quad C_{p v}[\mathrm{~kW}]$ & 13 & 13 & 13 \\
(B) Capacity of battery $C_{b t}[\mathrm{kWh}]$ & 0 & 0 & 0 \\
(C) Amount of battery discharge $E_{b t d}[\mathrm{~kW}]$ & 0 & 0 & 0 \\
(D) Amount of battery charge $E_{b t c}[\mathrm{~kW}]$ & 0 & 0 & 0 \\
(E) Capacity of fuel cell $C_{f c}[\mathrm{~kW}]$ & 146 & 143 & \\
Capacity of G/E generator $\quad C_{g e}[\mathrm{~kW}]$ & & & 776 \\
(F) Capacity of heat storage tank $C_{s t}[\mathrm{kWh}]$ & 66 & 0 & 62 \\
(G) Capacity of heat pump $C_{h p}[\mathrm{~kW}]$ & 470 & 454 & 0 \\
\hline Fuel consumption $f_{f c}, f_{g e}[\mathrm{kWh}]$ & 3087 & 4457 & 1478 \\
\hline
\end{tabular}

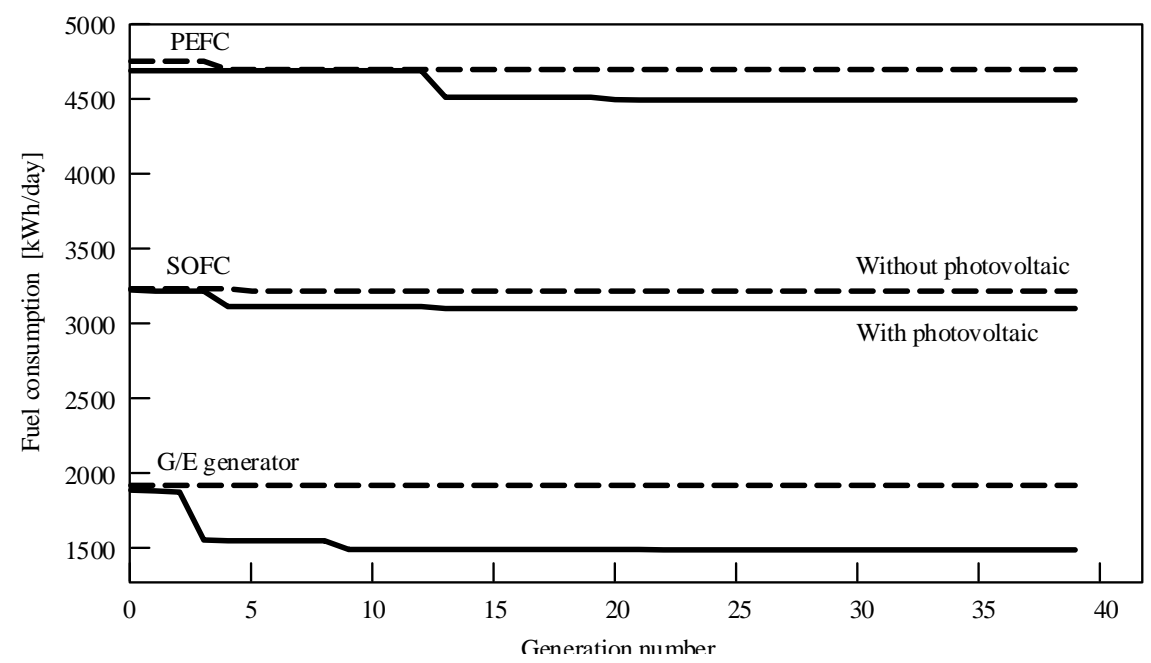

Fig. 12 Fuel consumption for each generation

Neither photovoltaics nor a battery were used in the optimal operation configuration, regardless of the kind of power supply that was chosen. When the cycling losses of the battery are taken into account, the accumulation term becomes disadvantageous. The Section was low for calculations involving photovoltaics because their capacity had only two levels in the orthogonal array. Therefore, the level of the design parameter (A) was changed to include three levels and the system was reanalyzed. Setting of the design parameter of two levels is very dangerous to search of the optimal solution, application of two levels should be avoided. The resulting generation number and fuel consumption are shown in Figure 12. Introducing photovoltaics decreases fuel consumption relative to the results shown in Table 5.

The optimal solution of each design parameter is shown in Table 6 for the scenario in which the second level of photovoltaics is $100 \mathrm{~kW}$. Compared with the disuse of photovoltaics in Fig. 5, the fuel consumption of the SOFC and PEFC decreased by $3.9 \%$ and 5\%, respectively. Moreover, when the G/E generator was used, the total fuel consumption decreased by $22.6 \%$. These findings indicate that equipment planning with only two levels decreases the analytical 
accuracy of the result.

\subsection{Optimal operation}

\section{(1) Power supply}

The analysis results for the optimal operation of power supplies and the heat pump are shown in Figure 13 based on the results of Table 6 . The exhaust heat output of each power supply and its load factor are shown in Fig. 14. The pattern of the heat load strongly influences the operation method of the power supply because the heat demand pattern (Fig. 8) is much larger than the electricity demand. Consequently, the load factor of the fuel cell in Figs. 14 (a) and (b) varies from $6 \%$ to $100 \%$ on a daily basis. In contrast, the operation of the G/E generator is planned so that a great amount of exhaust heat is produced with a relatively low loasetud factor. The generator is planned by heat load following operation by a large equipment capacity. The output ratio of electric power and heat from the power supplies influence the composition and capacity of heating equipment largely.

(2) Heating equipment

Figure 15 shows the results of the operation analysis of heat equipment. Because there are few amounts of exhaust heat of the SOFC and the PEFC to heat demand of the microgrid in this analysis case, the correspondence to heat load is largely based on the heat pump. Here, the heat exhaust means the thermal power of SOFC, PEFC, or G/E generator. On the other hand, the exhaust heat of the $\mathrm{G} / \mathrm{E}$ generator has exceeded the heat demand in almost all time periods. In the case of using G/E generator, the heat pump is not installed. The load factor of each fuel cell and COP of the heat pump are shown in Figure 16. The PEFC has more exhaust heat than the SOFC, so the load factor and COP of the PEFC are lower than those of the SOFC.

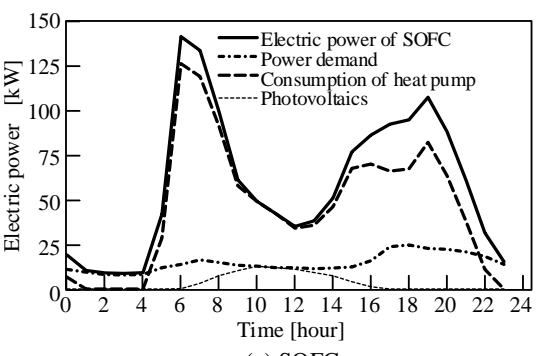

(a) SOFC
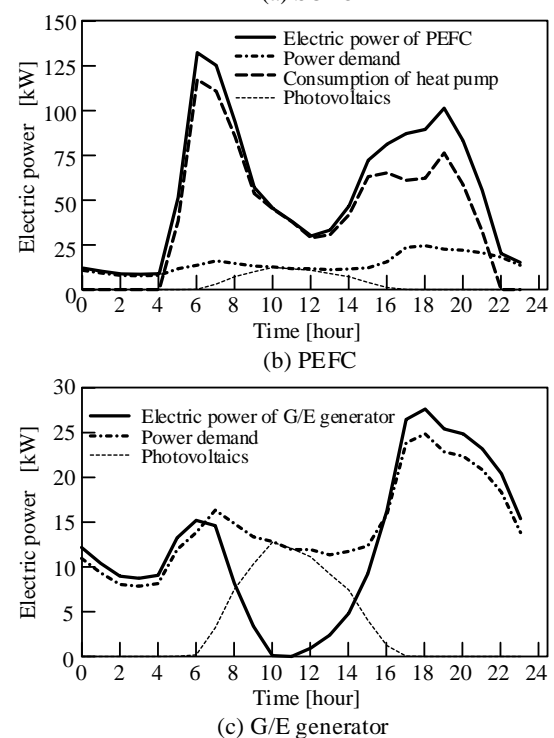

Fig. 13 Optimized operational results of the power equipment

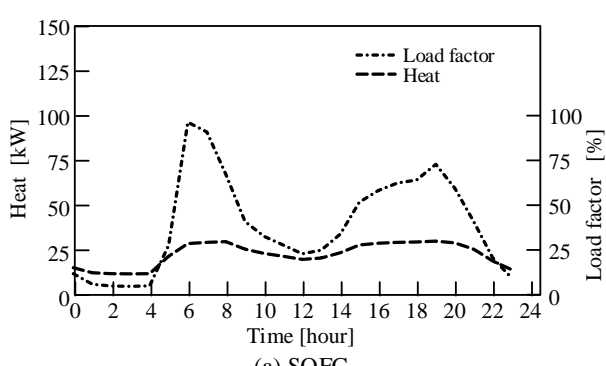

(a) SOFC

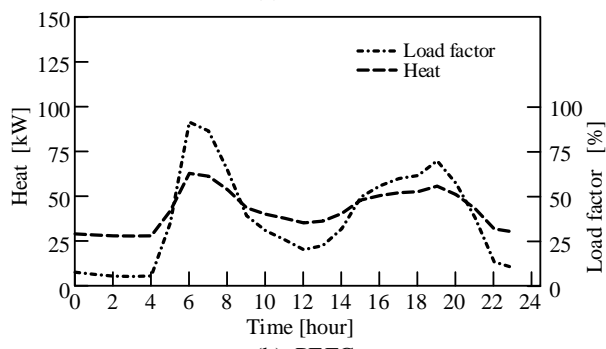

(b) PEFC

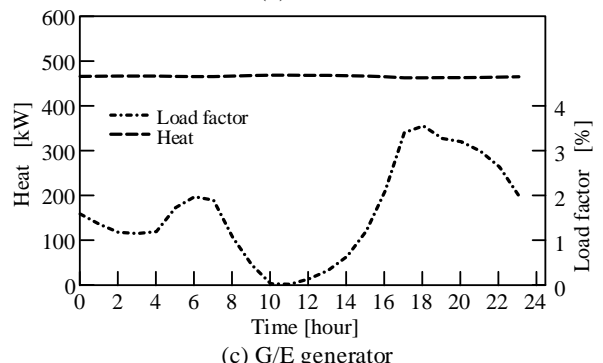

Fig. 14 Operational planning and load factors of the power equipment

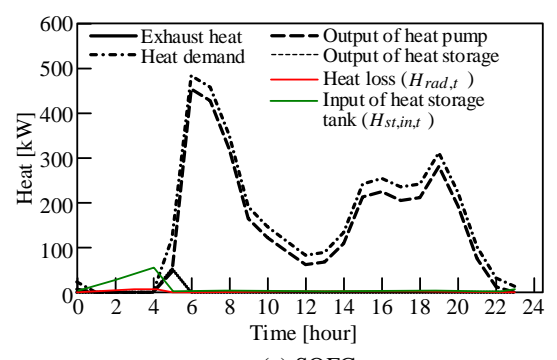

(a) SOFC

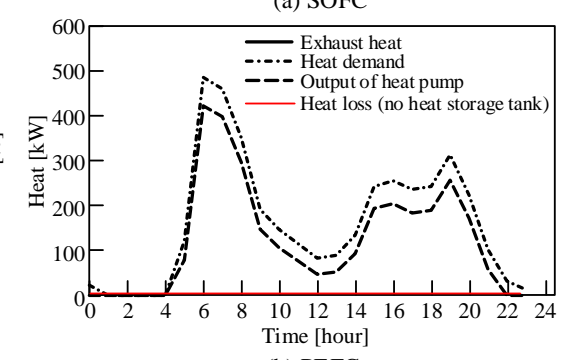

(b) PEFC

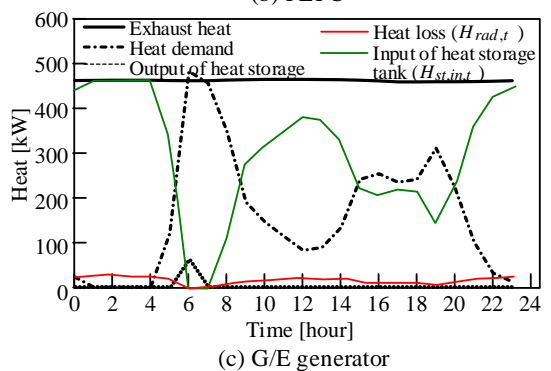

Fig. 15 Results of the operation analysis of heating equipment

\subsection{Verification of the analysis algorithm}

The frequency of convergence error between the conventional GA and the orthogonal array-GA hybrid analysis 
methods are shown in Figure 17. The analysis parameters are the generation number (40), the number of chromosomes (300), the probabilities of mutation and cross-over (0.3), and the number of trials (100). Conventional GA is applied to the analysis example and the solution fulfilled most decides the objective function to be the optimal solution. Because the conventional GA is an efficient algorithm of the random search by computer, the solution very near the optimal solution is obtained by much repeated calculation. The convergence error is a ratio of the difference of the optimal solution obtained by the much repeated calculation of the conventional GA, and the analysis result obtained in 100 analyses of each analysis method. Figure. 17 shows the frequency of appearance for every magnitude of the convergence error.

Analysis results for the SOFC and G/E generator always converge. However, the analysis results do not converge with respect to the PEFC; the convergence rate of the conventional GA is 1 in 8 trials, and that of the proposed method was 1 in 2 trials. According to Fig. 17, the convergence errors of the SOFC and PEFC are largely reduced by using the orthogonal array-GA hybrid analysis. Using the orthogonal array-GA hybrid analysis method with the SOFC, the convergence error is $2 \%$ or less for 73 of the 100 trials. On the other hand, the conventional GA provide a solution with the same convergence error for only 58 out of 100 trials. When the orthogonal array-GA hybrid analysis method is applied

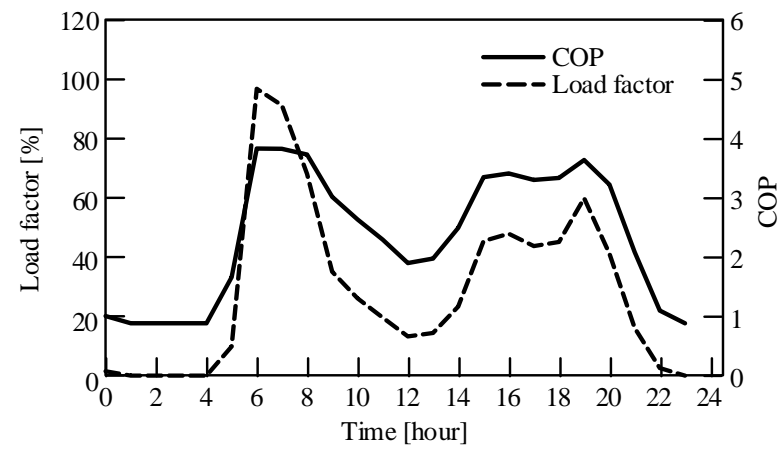

(a) Case of SOFC

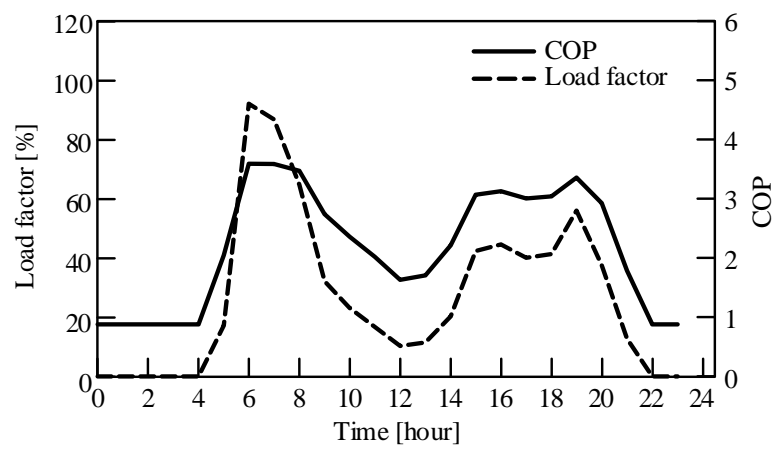

(b) Case of PEFC

Fig. 16 Analysis results of heat pump output and COP

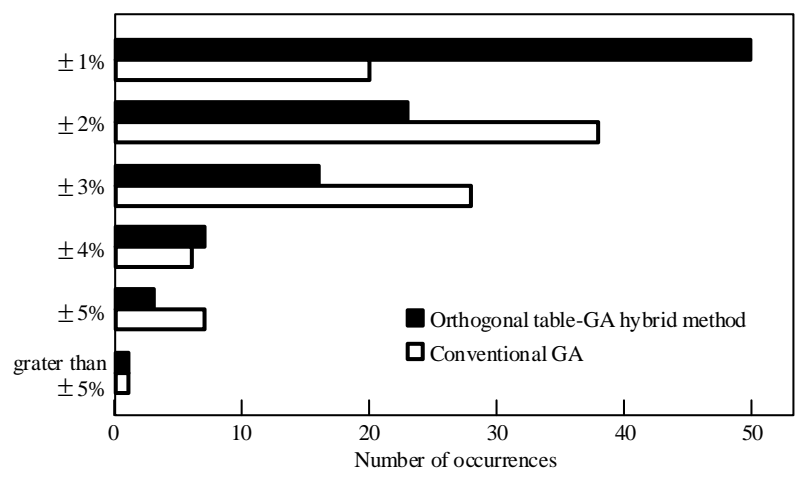

(a) SOFC

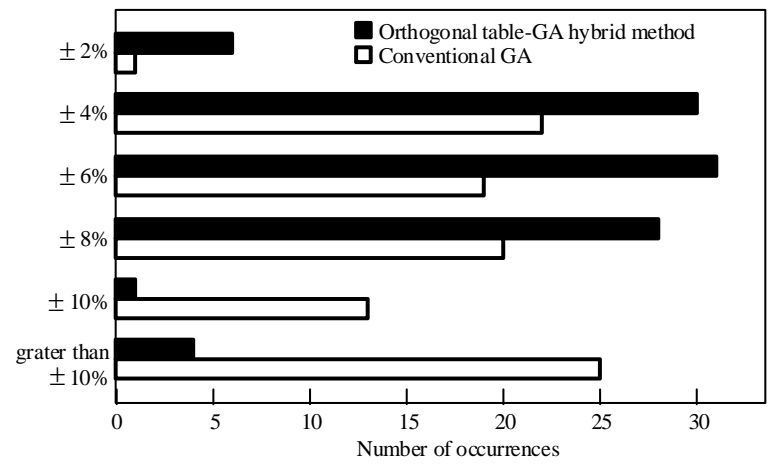

(b) PEFC

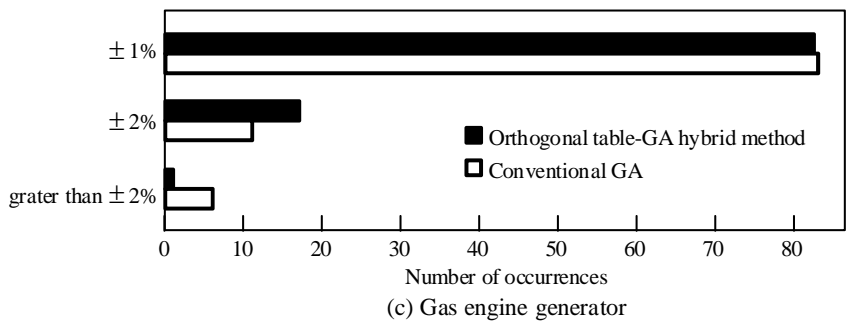

Fig. 17 Convergence error of the optimal solution (for 100 trials)

to the microgrid with the PEFC, the solution had less than $8 \%$ convergence error for 94 out of 100 trials. However, the same convergence error is obtained for conventional GA for only 65 out of 100 trials.

The convergence error of the G/E generator is sufficiently small using the conventional GA, so the proposed method 
is distinctly favorable in Fig. 17(c). The analytic accuracy of the operation planning is influenced by the output characteristics of the power supply. As shown in Fig. 12, the fuel consumption of the PEFC is the maximum. This reason is because the output ratio of heat and electric power of each power supply are largely different as shown in Fig. 7. Even though the power generation using the G/E generator has most fuel consumption, the electric power consumption of the heat pump decreases with a lot of exhaust heat. Therefore, the fuel consumption of the G/E generator is overall less than other power supplies. On the other hand, because the power-generation efficiency of the SOFC is high, fuel consumption is less than the PEFC. As a result, the fuel consumption of the PEFC increases more than other power supplies. Because the objective function of the analysis example is minimization of the fuel consumption (Eq. (23)), the convergence error will increase relatively when the fuel consumption increases. As a result, it is thought that the convergence error of the PEFC falls rather than other power supplies as shown in Fig. 17.

Optimization of operation and equipment capacity for a microgrid is a nonlinear problem that requires dynamic analysis with many variables. In this paper, an orthogonal array-GA hybrid analysis method was proposed. According to the proposed method, the design parameters were chosen to be the installed capacity of each piece of equipment. An orthogonal array and factorial-effect chart were used for numerical simulations of the experimental design to select parameter values that were near the optimal solution. These design parameters were used as initial values for a conventional GA. Although improved to the conventional GA regarding the proposal method of this paper, the strict optimal solution is not obtained. On the other hand, the real operation planning of an energy system contains the error of weather prediction (they use for power prediction of renewable energy), the disturbances regarding system control, etc., for example. Therefore, when the errors included in the operation planning of a real energy system are taken into consideration, it is thought that the magnitude of analysis error by the proposal method is not extremely bad. For the reason explained in the top, we judged that the analytic accuracy of this proposal method could apply industrially. As a result, the operation optimal solution of the microgrid exhibited analytical accuracy, which can be used industrially.

\section{Conclusions}

Generally, the output characteristics of the power sources are nonlinear. Furthermore, because multiple power sources are used in compound energy system as microgrids, many variables must be considered to optimize the system. Genetic algorithms (GA) provide a facile method for solving such problems and can be easily adapted to complicated energy systems. However, case of large system, requires lengthy analysis time, generates many suboptimal solution, and unsatisfactory solutions of energy balance equations are obtained. As this solution, reported the orthogonal table - GA hybrid analysis method for planning the optimal operation of a compound energy system in the previous study. The operation plan of each microgrid with an SOFC, PEFC, and G/E generator, each with different output characteristics, was analyzed to examine the analytical accuracy of the orthogonal array-GA hybrid method. The following conclusions were made.

The convergence error for the microgrid with an SOFC or PEFC was much less for the orthogonal array-GA hybrid analysis method than for the conventional GA. Using the orthogonal array-GA hybrid analysis method with an SOFC, the convergence error was $2 \%$ or less for 73 of the 100 trials. In contrast, the conventional GA provided a solution with the same convergence error for only 58 out of 100 trials. When the orthogonal array-GA hybrid analysis method was applied to a microgrid with a PEFC, the solution had less than $8 \%$ convergence error for 94 out of 100 trials. The same convergence error was obtained for conventional GA for only 65 out of 100 trials. The orthogonal array-GA hybrid analysis method exhibits a much higher analytic accuracy than the conventional GA. The analysis example of the microgrid indicates that the difference in the output characteristics of a power supply influences the analytic accuracy. These results can be directly applied to the operation of dynamic industrial scale energy grids with multiple heat and power sources.

\section{Nomenclature}

$\begin{array}{llll}C T & \text { Cost [US dollar (USD)] } & \lambda & \text { Operating period [Year] } \\ C & \text { Capacity [kW] } & \theta & \text { Unit fuel price [USD/kWh] } \\ C T_{k} & \text { Annual maintenance cost of system [USD] } & \text { Subscript } & \\ C O P & \text { Coefficient of performance } & b t & \text { Battery } \\ E & \text { Electric power [kW] } & b t c & \text { Charge of battery }\end{array}$




$\begin{array}{llll}\dot{E} & \text { Hourly electric power [kWh] } & b t d & \text { Discharge of battery } \\ e & \text { Experiment number } & c d & \text { Power conditioner } \\ F O B & \text { Objective function [USD] } & c o n v & \text { Comparison system } \\ f & \text { Fuel consumption [kWh] } & c r & \text { Chromosome } \\ f_{e k} & \text { Evaluation value of orthogonal array } & f c & \text { Fuel cell (SOFC or PEFC) } \\ & \text { [kWh] } & g e & \text { G/E power generator } \\ f_{p r, l s} & \text { Average evaluation cost [kWh] } & h & \text { Heat equipment } \\ H & \text { Heat [kW] } & h p & \text { Heat pump } \\ \Delta h & \text { Heat consumption [kW] } & i & \text { Number of equipment with consumption of } \\ I & \text { The number of equipment with consumption } & & \text { electric power } \\ & \text { of electric power } & & \text { Number of equipment with consumption of } \\ J & \text { The number of equipment with consumption } & j & \text { heat } \\ & \text { of heat } & & \text { Level value of design parameter } \\ N & \text { Total number } & l s & \text { Number of electric generator } \\ m & \text { Number of generator } & m & \text { Month } \\ n & \text { Number of heat equipment } & m h & \text { Number of heat equipment } \\ \Delta p & \text { Power consumption [kW] } & n & \text { Demand } \\ t & \text { Sampling time [Hour] } & n e e d s & \text { Generator } \\ x_{p} & \text { Level value [kW] } & p & \text { Payback } \\ \text { Greek characters } & \text { Weight factor } & p b & \text { Number of design parameter } \\ \alpha & \text { Cost on greenhouse gas emission [USD] } & p v & \text { Photovoltaics } \\ \phi & \text { Efficiency [-] } & r & \text { Multiplier of 2 } \\ \varphi & \text { Load factor [-] } & r a d & \text { Heat radiation } \\ \eta & & s t & \text { Heat storage tank }\end{array}$

\section{References}

Anastasopoulos M. P., Voulkidis A. C., Vasilakos V. A., Cottis G. P., A secure network management protocol for Smart Grid BPL networks: Design, implementation and experimental results, Computer Communications, Vo.31, (2008), pp.4333-4342.

Dante C. R., Escamilla L. J., Madrigal V., Theuss T., Calderón D. J., Solorza O., Rivera R., Fractional factorial design of experiments for PEM fuel cell performances improvement, International Journal of Hydrogen Energy, Vo.28, (2003), pp.343-348.

Hledik R., How Green Is the Smart Grid?. The Electricity Journal, Vol.22, (2009), pp.29-41.

Lin Y. C., Lay H. C., Effects of carbonate and phosphate concentrations on hydrogen production using anaerobic sewage sludge microflora, International Journal of Hydrogen EnergyVo.9, (2004), pp.275-281.

Maeda K., Masumoto K., Hayano A., A study on energy saving in residential PEFC cogeneration systems, Journal of Power Sources, Vo.95, (2010), pp.3779-3784.

Mitsubishi Electric Corporation, Chilling unit for air conditioning, available from $<$ http://www.mitsubishielectric.co.jp/ldg/ja/products/air/lineup/central/airchiller/lineup_02_print.html> (Referring Date 2016.3.24) (in Japanese).

Nair C. N. K., Zhang L., Smart Grid: Future networks for New Zealand power systems incorporating distributed generation, Energy Policy, Vo.37, (2009), pp.3418-3427.

Narita K., The Research on unused energy of the cold region city and utilization for the district heat and cooling, Ph. D. thesis, Hokkaido University, Sapporo, (1996).

Nazar S. M., Haghifam R. M., Multiobjective electric distribution system expansion planning using hybrid energy hub concept, Electric Power Systems Research Vo.79, (2009), pp.899-911.

NEDO Development of several 10kW-class system of disk-type intermediate-temperature SOFC (FY2008), Final report 2009. (in Japanese).

NEDO Technical information database, Standard meteorology and Solar radiation data (METPV-3), available from $<$ http://www.nedo.co.jp> (Referring Date 2016.3.24) (in Japanese).

Obara S., Watanabe S., Study on the Operation Analysis of a Compound Energy System Using Orthogonal Array-GA Hybrid Analyzing Method, Transactions of the Japan Society of Mechanical Engineers, Series B Vol.77, (2011), 
pp.2004-2018. (in Japanese)

Obara S, Watanabe S, Rengaraja B, Operation method study based on the energy balance of an independent microgrid using solar-powered water electrolyzer and an electric heat pump, Energy, Vol.36, (2011), pp.5200-5213.

Obara S., Watanabe S., Optimization of equipment capacity and an operational method based on cost analysis of a fuel cell microgrid, International Journal of Hydrogen Energy, Vol. 37 (2012), pp. 7814-7830.

Pascual J., Barricarte J., Sanchis P., Marroyo L., Energy management strategy for a renewable-based residential microgrid with generation and demand forecasting, Applied Energy Vo.158, (2015), pp.12-25.

Sachs J., Sawodny O., Multi-objective three stage design optimization for island microgrids, Applied Energy, Vol.165, (2016), pp.789-800.

Taguchi G., Experimental design, the third edition, Maruzen, ISBN-10: 4621082809, (2010) (in Japanese)

Wakui T., Yokoyama R., Optimal sizing of residential gas engine cogeneration system for power interchange operation from energy-saving viewpoint, Energy, Vo.36, (2011), pp.3816-3824.

Wang L., He M., Yang Z., Research on optimal calibration technology for hydrogen-fueled engine based on nonlinear programming theory, International Journal of Hydrogen Energy, Vo.35, (2010), pp.2747-2753.

Yang Z., Wang L., Li S., Investigation into the optimization control technique of hydrogen-fueled engines based on genetic algorithms, International Journal of Hydrogen Energy, Vo.33, (2008), pp.6780-6791.

Yu W. L., Wu S. J., Shiah S. W., Parametric analysis of the proton exchange membrane fuel cell performance using design of experiments, International Journal of Hydrogen Energy, Vo.3, (2008), pp.2311-2322. 